\title{
A Feasibility Study of a Bearingless Motor Based on Three-pole Active Magnetic Bearing
}

\section{Shyh-Leh Chen*, 1, Shang-Yu Hsu1, Pai-Lu Wang², and Darping Juang 2}

\author{
${ }^{1}$ Advanced Institute of Manufacturing with High-tech Innovations and Department of Mechanical Engineering, National Chung Cheng \\ University, Taiwan \\ ${ }^{2}$ Materials \& Electro-Optics Research Division, Chung-Shan Institute of Science and Technology, Taiwan \\ (Received 19 November 2011; Accepted 15 February 2012; Published on line 1 June 2012) \\ *Corresponding author: imeslc@ccu.edu.tw \\ DOI: 10.5875 /ausmt.v2i2.125
}

\begin{abstract}
The active magnetic bearing (AMB) offers several advantages such as having no friction, high rotational speed, less energy loss, and long life span. In rotation application, however, it must be connected to a motor which may degrade its performance. A bearingless motor is the combination of the active magnetic bearing and a motor. It saves software and hardware facilities, resulting in lower costs. In this paper, a permanent-magnet type bearingless motor is proposed based on a three-pole AMB. The translational magnetic field (generating the bearing forces) and the rotational magnetic field (generating the motor torque) are analyzed to establish the mathematical dynamic model of the overall system. Based on the dynamic model, a two-stage controller that sequentially levitates the rotor and controls the motor speed is designed. Numerical simulations are performed to verify the analysis.
\end{abstract}

Keywords: Active magnetic bearing; Bearingless motor; Three-pole

\section{Introduction}

Bearing is an important element for high-speed spindle machine tools or storage devices. Conventional bearings suffer the problems of wear and short lifetime due to the contact between bearing and rotor. There are several types of non-contact bearings such as hydrodynamic, air, and magnetic bearings. The non-contact bearings can reduce or eliminate the problems of friction, vibration, and acoustic noise. Among them, the active magnetic bearing ( $A M B$ ) is the most promising due to the advantages of high load capacity, large stiffness, and no lubrication. The disadvantage, however, is that it is expensive. To reduce AMB's cost, a 3-pole AMB has been proposed [1, 2]. The 3-pole $A M B$ possesses the advantages of having fewer power amplifiers and lower heat dissipation, leading to

www.ausmt.org

Copyright (C) 2012 International Journal of Automation and Smart Technology lower cost [1]. To further reduce the cost, a bearingless motor based on the cost-effective 3-pole $A M B$ is considered in this study.

A bearingless motor is a device that combines the function of motor and $\mathrm{AMB}$. It can save software and hardware facilities, resulting in lower cost. Since 1990, bearingless motors have been extensively studied. Most bearingless motors are simply the direct integration of motor and $\mathrm{AMB}$. In other words, the translation and rotational forces are generated by two independent sets of coils and/or permanent magnets. The levitation forces of most bearingless motors are reluctance forces, but the rotational torque can be Lorentz or reluctance type. According to the way the torque is generated, bearingless motors can be classified into three types: reluctance type, induction type, and permanent-magnet (PM) type. 
The reluctance type bearingless motor uses non-uniform magnetic reluctances between rotor and stator to generate the required torque [3-7]. As a result, its rotor must be designed with salient poles. The motoring torque is usually produced by the non-uniform magnetic reluctance. The magnetic flux must pass through the path with the least reluctance, so the salient pole on the rotor will be engaged and rotation torque is generated. For the reluctance type self-bearing motor, additional windings are added on the stator to provide radial suspension force. Both the motoring torque and levitation force are produced by reluctance force, and they can be reinforced simultaneously. There are many advantages for this type. First, it has the characteristic of being fail-safe and can easily brake in case of emergency. Also, it is low-cost from having no coils or permanent magnet on the rotor, as well as being easy to manufacture. Additionally, both translational and rotational torques can be enhanced simultaneously since they are both reluctance force. Furthermore, the temperature effect is insignificant compared to the PM type. The main disadvantage of the reluctance type bearingless motor is that there exists strong coupling between the rotational flux and levitation that is difficult for analysis. Also, the effect of cogging force cannot be neglected. A strong cogging effect and serious coupling between the rotational and levitation flux make it extremely difficult for analysis.

The induction type bearingless motor uses the coil windings on the stator to induce magnetic flux in the coil

Shyh-Leh Chen was born on October 25, 1964, in Keelung, Taiwan. He received the B.S and M.S. degrees in power mechanical engineering from National Tsing-Hua University, Hsin-Chu, Taiwan, in 1987 and 1989, respectively, and the Ph.D. degree in mechanical engineering from Michigan State University, East Lansing, USA, in 1996. Since 1996, he has been with National Chung Cheng University, Chiayi, Taiwan, where he is currently a Professor in the Department of Mechanical Engineering, Advanced Institute of Manufacturing with High-tech Innovations, and Director of Advanced Machine Tools Research Center. His research interests include nonlinear dynamics and control, wavelet analysis, with application to contouring control of multi-axis systems, active magnetic bearings, and ship stabilization.

Shang-Yu Hsu received B.S. from Chung Yuan Christian University, Taiwan, and M.S. from National Chung Cheng University, Taiwan, in 2005 and 2007, respectively, both in mechanical engineering. Currently, he works as a production engineer in manufacturing industry.

Pai-Lu Wang possesses a Ph.D. degree in mechanical engineering, and has been working in CHUNG-SHAN INSTITUTE OF SCIENCE \& TECHNOLOGY for over 27 years. Composite technology is his professional specialty, and he also has made efforts in study of flywheel technology for several years. Currently, he leads several R\&D groups in high temperature materials field.

Darping Juang possesses a M.S. degree in mechanical engineering, and has been working in CHUNG-SHAN INSTITUTE OF SCIENCE \& TECHNOLOGY. Composite technology is his professional specialty, and he also has made efforts in study of flywheel technology for several years. Currently, he leads several R\&D groups in composite field and battery field. windings on the rotor to generate the torque. It is based on Faraday's induction law and Lorentz principle for the rotational torque [8-15]. Additional coil windings are included on the stator to provide radial suspension force by reluctance force. Induction type bearingless motors have the advantages of low-cost, no permanent magnets, easy design, and larger radial suspension force. However, energy losses are considerably large because of slip. Also, the rotational flux and levitation flux are strongly coupled making complicated vector control necessary.

The PM type bearingless motor uses the permanent magnet on the rotor to generate the torque through the Lorentz principle, similar to that of the PM motor. In addition, several additional windings on the stator exist to provide reluctance forces for rotor levitation. The main advantage here is that the torque and levitation force can be controlled independently. According to the location of the permanent magnet on the rotor, the PM type bearingless motor can be classified into several types, including surface permanent magnet type [16, 17], inset permanent magnet type [18], interior permanent magnet type [19], consequent-pole type [20], and toothless type [21, 22]. In general, if the thickness of the permanent magnet is larger, larger torque can be produced, although the radial suspension force will become smaller. The design of toothless type can eliminate this effect because this type of bearingless motor uses Lorentz force to provide both motor torque and levitation force. These types of bearingless motors are different in the coupling effect between the rotational flux and levitation flux, making modeling and controller design difficult. The main advantage of the PM type is that the flux coupling effect is less significant, leading to easier analysis and control. Here, the surface PM type is adopted in this work.

In this study, a PM type bearingless motor based on a 3-pole $A M B$ is proposed and analyzed, modified from a conventional 3-pole AMB. To become a bearingless motor, the 3-pole $A M B$ must be able to produce rotational torque for motor function, in addition to the levitation forces for bearing function. Due to the special 3-pole structure, the 3-pole AMB can be easily integrated with the 3-phase currents to generate the motor function. The proposed bearingless motor is expected to inherit the advantage of the low costs of the 3-pole AMB and bearingless motor.

The paper is organized as follows. After the introduction, the bearingless motor system is described in Section II, followed by its dynamic modeling in Section III. In Section IV, the controllers for levitation and speed control with numerical simulations are presented. Finally, conclusions are drawn in Section V. 


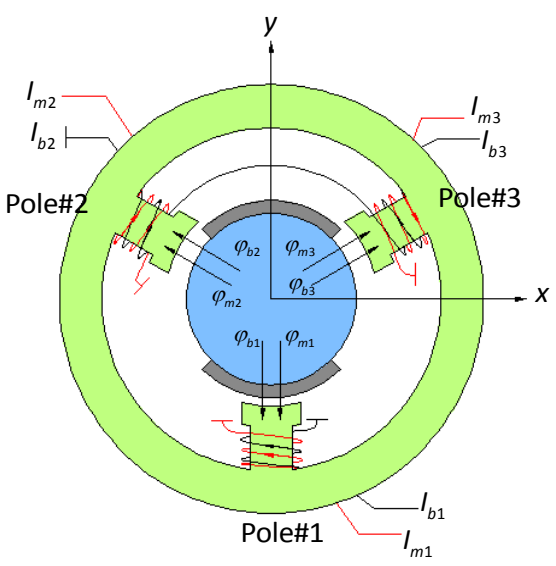

Figure 1. The 3-pole bearingless motor.

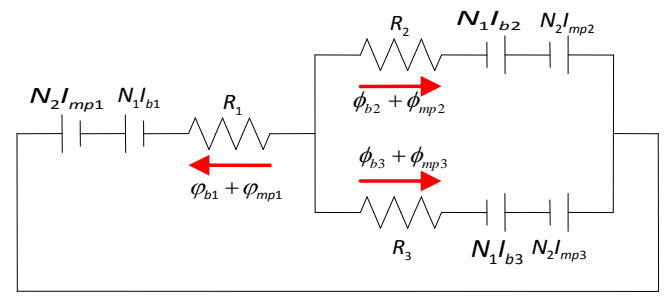

Figure 2. Magnetic circuit for the bearingless motor.

\section{System Description}

Figure 1 shows the proposed bearingless motor. A pair of permanent magnets is mounted on the surface of the rotor. There are two sets of coil windings on the three poles of the stator. The first set, called bearing currents, is the same as that in the conventional 3-pole $\mathrm{AMB}$, with one independent coil on pole $\# 1, I_{b 1}=i_{b 1}$, and the other independent coil on poles \#2 and \#3 configured as, $I_{b 2}=-I_{b 3}=i_{b 2}$. This set mainly provides the levitation force. The other set, called motor currents, is the usual 3-phase winding for the rotational torque:

$$
\begin{aligned}
& I_{m 1}=i_{m} \cos (\theta) \\
& I_{m 2}=i_{m} \cos \left(\theta+\frac{2 \pi}{3}\right) \\
& I_{m 3}=i_{m} \cos \left(\theta-\frac{2 \pi}{3}\right)
\end{aligned}
$$

where $\theta$ is the rotor angle and $i_{m}$ is the amplitude of the 3-phase motor current. In other words, $i_{b 1}, i_{b 2}$ and $i_{m}$ will be the three control inputs of the bearingless motor system. A controller is designed for them to achieve stable levitation (AMB function) and constant rotation speed (motor function).

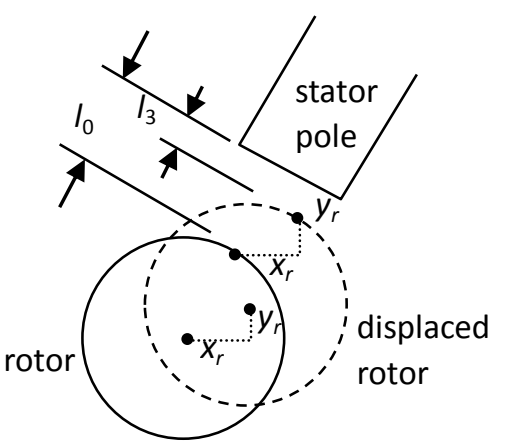

Figure 3. Illustration of rotor displacement and air gap.

\section{Dynamic Modeling}

In order to get the dynamic model of the bearingless motor, we need to obtain the models of levitation forces and rotational torque. For the magnetic levitation forces, the magnetic flux on each pole is first obtained by magnetic circuit analysis, as shown in Figure 2, which yields:

$$
\begin{aligned}
{\left[\begin{array}{l}
\varphi_{1} \\
\varphi_{2} \\
\varphi_{3}
\end{array}\right] } & =\frac{N_{1}}{R_{n}}\left[\begin{array}{ccc}
R_{2}+R_{3} & -R_{3} & -R_{2} \\
-R_{3} & R_{1}+R_{3} & -R_{1} \\
-R_{2} & -R_{1} & R_{1}+R_{2}
\end{array}\right]\left[\begin{array}{c}
i_{b 1} \\
i_{b 2} \\
-i_{b 2}
\end{array}\right] \\
& +\frac{N_{2}}{R_{n}}\left[\begin{array}{ccc}
R_{2}+R_{3} & -R_{3} & -R_{2} \\
-R_{3} & R_{1}+R_{3} & -R_{1} \\
-R_{2} & -R_{1} & R_{1}+R_{2}
\end{array}\right]\left[\begin{array}{l}
I_{m 1}+I_{p 1} \\
I_{m 2}+I_{p 2} \\
I_{m 3}+I_{p 3}
\end{array}\right],
\end{aligned}
$$

where $\varphi_{1} \sim \varphi_{3}$ are magnetic fluxes, $i_{b 1}, i_{b 2}$ are the bearing currents, $I_{m 1} \sim I_{m 3}$ are the motor currents given by (1), $I_{p 1} \sim I_{p 3}$ are the equivalent coil currents for the permanent magnets to be defined later, $N_{1}$ is the number of bearing coils, and $N_{2}$ is the number of motor coils, and $R_{n}=R_{1} R_{2}+R_{2} R_{3}+R_{3} R_{1} . R_{1} \sim R_{3}$ are magnetic resistance defined by [2] as:

$$
\begin{aligned}
& R_{1}=\frac{1}{\mu A}\left(I_{0}+y_{r}\right) \\
& R_{2}=\frac{1}{\mu A}\left(I_{0}+\frac{\sqrt{3}}{2} x_{r}-\frac{1}{2} y_{r}\right), \\
& R_{3}=\frac{1}{\mu A}\left(I_{0}-\frac{\sqrt{3}}{2} x_{r}-\frac{1}{2} y_{r}\right)
\end{aligned}
$$

where $x_{r}$ and $y_{r}$ are the rotor displacements, as illustrated in Figure $3, I_{0}$ is the nominal air gap between rotor and stator, $\mu$ is the magnetic permeability of the air and $A$ is the pole face area. For easy analysis of the levitation forces, the equivalent coil currents for the permanent magnets are used: 


$$
\begin{aligned}
& I_{p 1}=i_{p} \sin (\theta) \\
& I_{p 2}=i_{p} \sin \left(\theta+\frac{2 \pi}{3}\right), \\
& I_{p 3}=i_{p} \sin \left(\theta-\frac{2 \pi}{3}\right)
\end{aligned}
$$

which possess a phase lag of 90 degrees with the motor currents. In other words, with the currents given by (4) applied to the motor coils, the generated magnetic flux will be the same as that by the permanent magnets on the rotor. By Ampere's law, it can be shown that the amplitude of the equivalent current, $i_{p}$, and the magnetic flux of the permanent magnets, $\varphi_{p}$, are related by:

$$
i_{p}=\frac{4 I_{0}}{3 \mu A_{1} N_{2}} \varphi_{p}
$$

Then, the magnetic reluctance force of each pole is given by the principle of virtual work as:

$$
F_{i}=\frac{\varphi_{i}^{2}}{2 \mu A}, i=1 \sim 3,
$$

and the reluctance levitation forces can be obtained by:

$$
\begin{aligned}
F_{x} & =\left(F_{3}-F_{2}\right) \cos 30^{\circ}=\frac{\sqrt{3}}{4 \mu A}\left(\varphi_{3}^{2}-\varphi_{2}^{2}\right)=m c_{b} \Psi_{1} \Psi_{2}, \\
F_{y} & =\left(F_{2}+F_{3}\right) \sin 30^{\circ} \\
& =\frac{1}{4 \mu A}\left[\left(\varphi_{3}^{2}+\varphi_{2}^{2}\right)-2 \varphi_{1}^{2}\right]=\frac{m c_{b}}{2}\left(\Psi_{2}^{2}-\Psi_{1}^{2}\right)
\end{aligned}
$$

where $m$ is the rotor mass, $c_{b}=\frac{4 \mu A N_{1}^{2}}{3 m}$, and

$$
\begin{aligned}
{\left[\begin{array}{l}
\Psi_{1} \\
\Psi_{2}
\end{array}\right]=} & \frac{-1}{L}\left[\begin{array}{cc}
2 I_{0}-y_{r} & \sqrt{3} x_{r} \\
x_{r} & \sqrt{3}\left(2 I_{0}+y_{r}\right)
\end{array}\right]\left[\begin{array}{l}
i_{b 1} \\
i_{b 2}
\end{array}\right], \\
& +\frac{N_{r} i_{m}}{L}\left[\begin{array}{l}
M_{1} \\
M_{2}
\end{array}\right]+\frac{N_{r} i_{p}}{L}\left[\begin{array}{l}
P_{1} \\
P_{2}
\end{array}\right]
\end{aligned}
$$

where $L=4 I_{0}^{2}-\left(x_{r}^{2}+y_{r}^{2}\right), \quad N_{r}=N_{2} / N_{1}$, and

$$
\left[\begin{array}{l}
M_{1} \\
M_{2}
\end{array}\right]=\left[\begin{array}{l}
\left(-2 I_{0}+y_{r}\right) \cos \theta+\left(I_{0}-\frac{\sqrt{3}}{2} x_{r}-\frac{1}{2} y_{r}\right) \cos \left(\theta+\frac{2 \pi}{3}\right) \\
+\left(I_{0}+\frac{\sqrt{3}}{2} x_{r}-\frac{1}{2} y_{r}\right) \cos \left(\theta-\frac{2 \pi}{3}\right) \\
-x_{r} \cos \theta+\left(-\sqrt{3} I_{0}+\frac{1}{2} x_{r}-\frac{\sqrt{3}}{2} y_{r}\right) \cos \left(\theta+\frac{2 \pi}{3}\right) \\
+\left(\sqrt{3} I_{0}+\frac{1}{2} x_{r}+\frac{\sqrt{3}}{2} y_{r}\right) \cos \left(\theta-\frac{2 \pi}{3}\right)
\end{array}\right]
$$

$$
\left[\begin{array}{l}
P_{1} \\
P_{2}
\end{array}\right]=\left[\begin{array}{l}
\left(-2 I_{0}+y_{r}\right) \sin \theta+\left(I_{0}-\frac{\sqrt{3}}{2} x_{r}-\frac{1}{2} y_{r}\right) \sin \left(\theta+\frac{2 \pi}{3}\right) \\
+\left(I_{0}+\frac{\sqrt{3}}{2} x_{r}-\frac{1}{2} y_{r}\right) \sin \left(\theta-\frac{2 \pi}{3}\right) \\
-x_{r} \sin \theta+\left(-\sqrt{3} I_{0}+\frac{1}{2} x_{r}-\frac{\sqrt{3}}{2} y_{r}\right) \sin \left(\theta+\frac{2 \pi}{3}\right) \\
+\left(\sqrt{3} I_{0}+\frac{1}{2} x_{r}+\frac{\sqrt{3}}{2} y_{r}\right) \sin \left(\theta-\frac{2 \pi}{3}\right)
\end{array}\right] .
$$

Equation (6) clearly reveals the contribution to the levitation forces from different sources. The first term of (6) represents the contribution of bearing currents, the second term represents that of motor currents, and the last term represents that of permanent magnets. The latter two forces need to be compensated for by the bearing currents through controller design, as discussed in Section IV below. When the motor currents and permanent magnets are removed $\left(i_{m}=i_{p}=0\right)$, Equations (5) and (6) will reduce to the case of a conventional 3-pole AMB [2].

When the rotor is at rest, bearing and motor currents are not present, but the PM force still exists. As such, it will get stuck to the stator. This force is in general very strong. A common practice for $A M B$ is to design a back-up bearing between the rotor and $A M B$ to avoid the direct contact of the rotor and stator. The nominal air gap of the back-up bearing is usually designed to be half of that of AMB. With the back-up bearing, the PM force at rest will not be as large as that with direct contact. Even so, the AMB still needs to overcome this force in order to levitate the rotor. In other words, the bearing currents must be able to provide the AMB force that is larger than the PM force.

The rotational torque can be obtained by the Lorentz principle, which is the interaction of the PM magnetic field on the rotor and the coil currents on the stator poles. Similar to the levitation forces, both motor currents and bearing currents will contribute to the rotation torque. The torque generated by the motor currents is given by:

$$
\begin{aligned}
T_{m}= & r l B_{p} N_{2} i_{m}\left[\cos \theta \cos \left(\frac{\pi}{2}-\theta-\beta\right)-\cos \theta \cos \left(\frac{\pi}{2}-\theta+\beta\right)\right. \\
& +\cos \left(\theta+\frac{2 \pi}{3}\right) \cos \left(\frac{\pi}{6}+\theta+\beta\right)-\cos \left(\theta+\frac{2 \pi}{3}\right) \cos \left(\frac{\pi}{6}+\theta-\beta\right) \\
& \left.+\cos \left(\theta-\frac{2 \pi}{3}\right) \cos \left(\theta-\frac{\pi}{6}-\beta\right)-\cos \left(\theta-\frac{2 \pi}{3}\right) \cos \left(\theta-\frac{\pi}{6}+\beta\right)\right] \\
& =\left(3 r l B_{p} N_{2} \sin \beta\right) i_{m}
\end{aligned}
$$

where $r$ is the rotor radius, $I$ is the thickness of the stator, $B_{p}$ is the flux density of the permanent magnet, and $\beta$ is the angle of the half span of each magnetic 
pole. The first two terms in the bracket are the contribution of the motor current on pole \#1, and similar statements apply to pole \#2 and \#3. Next, the torque generated by the bearing currents is given by

$$
\begin{aligned}
T_{b}= & r I B_{p} N_{1}\left[i_{b 1} \cos \left(\frac{\pi}{2}-\theta-\beta\right)-i_{b 1} \cos \left(\frac{\pi}{2}-\theta+\beta\right)\right. \\
& +i_{b 2} \cos \left(\frac{\pi}{6}+\theta+\beta\right)-i_{b 2} \cos \left(\frac{\pi}{6}+\theta-\beta\right) \\
& \left.-i_{b 2} \cos \left(\theta-\frac{\pi}{6}-\beta\right)+i_{b 2} \cos \left(\theta-\frac{\pi}{6}+\beta\right)\right] \\
& =\left(2 r l B_{p} N_{1} \sin \beta \cos \theta\right) i_{b 1}-\left(2 \sqrt{3} r / B_{p} N_{1} \sin \beta \sin \theta\right) i_{b 2}
\end{aligned}
$$

The first two terms in the bracket are the contribution of bearing current on pole \#1, and similar statements apply to pole \#2 and \#3. Finally, combining the above two equations, we have the total generated torque given by

$$
\begin{aligned}
T_{t}= & \left(3 r l B_{p} N_{2} \sin \beta\right) i_{m}+\left(2 r l B_{p} N_{1} \sin \beta \cos \theta\right) i_{b 1} \\
& -\left(2 \sqrt{3} r l B_{p} N_{1} \sin \beta \sin \theta\right) i_{b 2}
\end{aligned}
$$

The first term in the torque equation is the contribution of the motor currents. The last two terms represent the coupling of the bearing currents to the motor torque. As one can see from (11), both $i_{b 1}$ and $i_{b 2}$ will contribute to the torque which depends on the rotor angle $\theta$. This implies that they will cause torque ripple that needs to be compensated for.

With the forces and torque in hand, the dynamic model of the system can be obtained as

$$
\begin{aligned}
& \ddot{x}_{r}=\frac{F_{x}}{m}=c_{b} \Psi_{1} \Psi_{2} \\
& \ddot{y}_{r}=\frac{F_{y}}{m}-g=\frac{c_{b}}{2}\left(\Psi_{2}^{2}-\Psi_{1}^{2}\right)-g, \\
& \ddot{\theta}=\frac{1}{J} T_{t}-\frac{B}{J} \dot{\theta}
\end{aligned}
$$

where $J$ is the mass moment of inertia of the rotor shaft and $B$ is the damping coefficient of the motor. Let the state variables be $x_{1}=x_{r}, x_{2}=\dot{x}_{r}, x_{3}=y_{r}, x_{4}=\dot{y}_{r}$, $x_{5}=\theta$, and $x_{6}=\dot{\theta}$. Then Equation (12) can be expressed in the state space form as:

$$
\dot{x}=\left[\begin{array}{c}
x_{2} \\
c_{b} \Psi_{1} \Psi_{2} \\
x_{4} \\
\frac{c_{b}}{2}\left(\Psi_{2}^{2}-\Psi_{1}^{2}\right)-g \\
x_{6} \\
-\frac{B}{J} x_{6}+\frac{1}{J} T_{t}
\end{array}\right] .
$$

\section{Controller Design}

It is assumed that the operation of the bearingless motor levitates the rotor to the bearing center first, and then the 3-phase current is provided to activate the motor. In other words, the operation of the system is decomposed into two stages: levitation and rotation. At the levitation stage, the motor dynamics are neglected and the feedback linearization approach is adopted. With the feedback linearization action, the $X$ and $Y$ rotor dynamics are decoupled and the integral sliding mode controller for both dynamics is designed. At the rotation stage, the bearing currents $i_{b 1}$ and $i_{b 2}$ are assumed given and a simple PD controller is designed for $T_{t}$ (and hence for $i_{m}$ ) to achieve the motor speed control.

At the levitation stage, $i_{m}=0$, and as such, the motor dynamics are neglected at this stage. As a result, the levitation controller is almost the same as that used in a conventional 3-pole AMB [1]. The only difference is that one needs to compensate for the coupling effects of the PM. The levitation controller is designed with two steps. First, $\Psi_{1}$ and $\Psi_{2}$ are regarded as the virtual control inputs and the feedback linearization approach is taken. In other words, it is to find solution for $\Psi_{1}$ and $\Psi_{2}$ such that:

$$
\begin{aligned}
& c_{b} \Psi_{1} \Psi_{2}=\tilde{i}_{1} \\
& \frac{c_{b}}{2}\left(\Psi_{2}^{2}-\Psi_{1}^{2}\right)-g=\tilde{i}_{2} .
\end{aligned}
$$

Then, the integral sliding mode control is employed as:

$$
\begin{aligned}
& {\left[\begin{array}{l}
\tilde{i}_{1} \\
\tilde{i}_{2}
\end{array}\right]=-b_{1} \xi-b_{2} \eta-\frac{\rho+\alpha}{1-k} \operatorname{sat}\left(\frac{\xi+b_{1} \eta+b_{2} z}{\varepsilon}\right)} \\
& \dot{z}=\eta
\end{aligned}
$$

where:

$$
\eta=\left[\begin{array}{ll}
\eta_{1} & \eta_{2}
\end{array}\right]^{T}=\left[\begin{array}{ll}
x_{1} & x_{3}
\end{array}\right]^{T}, \quad \xi=\left[\begin{array}{ll}
\xi_{1} & \xi_{2}
\end{array}\right]^{T}=\left[\begin{array}{ll}
x_{2} & x_{4}
\end{array}\right]^{T}
$$

and $b_{1}, b_{2}, \rho, \varepsilon, \alpha, k$ are control parameters. With this solution for $\Psi_{1}$ and $\Psi_{2}$, Equation (6) can be utilized to obtain the control law for the actual control inputs $i_{b 1}$ and $i_{b 2}$. For more details, please refer to [1]. The overall control law is

$$
\begin{array}{r}
{\left[\begin{array}{l}
i_{b 1} \\
i_{b 2}
\end{array}\right]=\frac{1}{\sqrt{c_{b}}}\left[\begin{array}{cc}
-2 I_{0}-y_{r} & x_{r} \\
\frac{x_{r}}{\sqrt{3}} & \frac{-2 I_{0}+y_{r}}{\sqrt{3}}
\end{array}\right]\left[\begin{array}{l}
p\left(\tilde{i}_{1}, \tilde{i}_{2}\right) \\
q\left(\tilde{i}_{1}, \tilde{i}_{2}\right)
\end{array}\right]} \\
-\frac{N_{r} i_{p}}{L}\left[\begin{array}{cc}
-2 I_{0}-y_{r} & x_{r} \\
\frac{x_{r}}{\sqrt{3}} & \frac{-2 I_{0}+y_{r}}{\sqrt{3}}
\end{array}\right]\left[\begin{array}{l}
P_{1} \\
P_{2}
\end{array}\right],
\end{array}
$$


where $P_{1}$ and $P_{2}$ are given by Equation (8), and

$$
\left[\begin{array}{c}
p\left(\tilde{i}_{1}, \tilde{i}_{2}\right) \\
q\left(\tilde{i}_{1}, \tilde{i}_{2}\right)
\end{array}\right]=\left[\begin{array}{c}
\sqrt{-\left(\tilde{i}_{2}+g\right)+\sqrt{\left(\tilde{i}_{2}+g\right)^{2}+\tilde{i}_{1}^{2}}} \operatorname{sgn}\left(\tilde{i}_{1}\right) \\
\sqrt{\left(\tilde{i}_{2}+g\right)+\sqrt{\left(\tilde{i}_{2}+g\right)^{2}+\tilde{i}_{1}^{2}}}
\end{array}\right] .
$$

Equation (16) reveals that the control currents are composed of two parts. The first term is for the stabilization of the levitation dynamics. The second term is for the compensation of the PM force, as mentioned previously.

At the rotation stage, it is assumed that the rotor is maintained at the bearing center, or in other words, that the levitation dynamics have reached a steady state. Hence, $i_{b 1}$ and $i_{b 2}$ are given at this stage. Then, the control law for the overall torque $T_{t}$ for the motor dynamics, the third equation in Equation (12), can be obtained. Here, a simple PD controller is designed for $T_{t}$ to achieve the motor speed control. Finally, by Equation (11), one can get the control law for the motor current $i_{m}$.

Simulation results for the levitation control are presented in Figures 4 and 5, where Figure 4 shows the rotor trajectory during levitation and Figure 5 shows the corresponding bearing currents. In the simulations, the system parameters are given in Table 1 , with the control parameters of: $b_{1}=20, b_{2}=20, \rho=5, \alpha=3$, $k=0.5, \varepsilon=0.1$. The dotted line (circle) in Figure 3 represents the allowable range of the rotor limited by the back-up bearing. Note that the nominal air gap between the rotor and the back-up bearing is $0.5 \mathrm{~mm}$.

Figures 6 and 7 are the simulation results of motor control with speed command of $1000 \mathrm{rad} / \mathrm{s}$, where Figure 6 shows the time response of angular displacement and the rotor speed, and Figure 7 shows the corresponding motor currents. Here, it is assumed that no external load is applied. If there is external load, additional motor currents in Figure 7 are needed to achieve the same speed. The results indicate that the proposed 3-pole bearingless motor is feasible.

Table 1. System parameters.

\begin{tabular}{|l|l|}
\hline$I_{0}=0.95 \times 10^{-3} \mathrm{~m}$ & $\mu=4 \pi \times 10^{-7} \mathrm{H} / \mathrm{m}$ \\
\hline$A=4 \times 10^{-4} \mathrm{~m}^{2}$ & $B_{p}=0.5$ Tesla \\
\hline$J=3.94 \times 10^{-4} \mathrm{~kg} \cdot \mathrm{m}^{2}$ & $B=0.002 \mathrm{~N} \cdot \mathrm{m} / \mathrm{rad} / \mathrm{s}$ \\
\hline$m=0.6435 \mathrm{~kg}$ & $\mathrm{~g}=9.81 \mathrm{~m} / \mathrm{s}^{2}$ \\
\hline$N_{1}=300$ & $N_{2}=300$ \\
\hline$r=0.035 \mathrm{~m}$ & $I=0.02 \mathrm{~m}$ \\
\hline$\beta=32^{\circ}$ & $R_{m}=2 \Omega$ \\
\hline
\end{tabular}

www.ausmt.org

Copyright (c) 2012 International Journal of Automation and Smart Technology

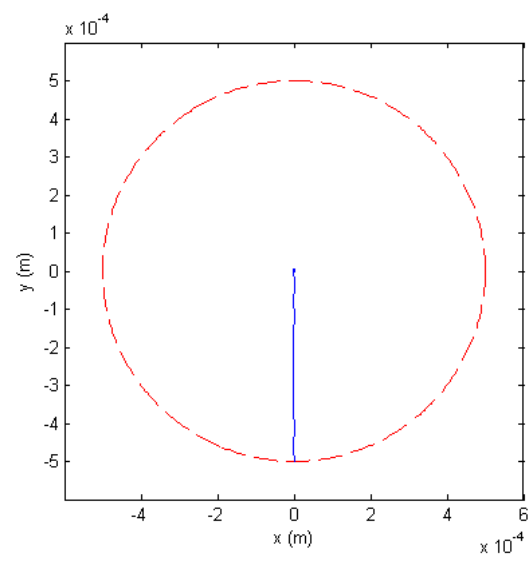

Figure 4. The rotor trajectory with ISMC at the levitation stage.
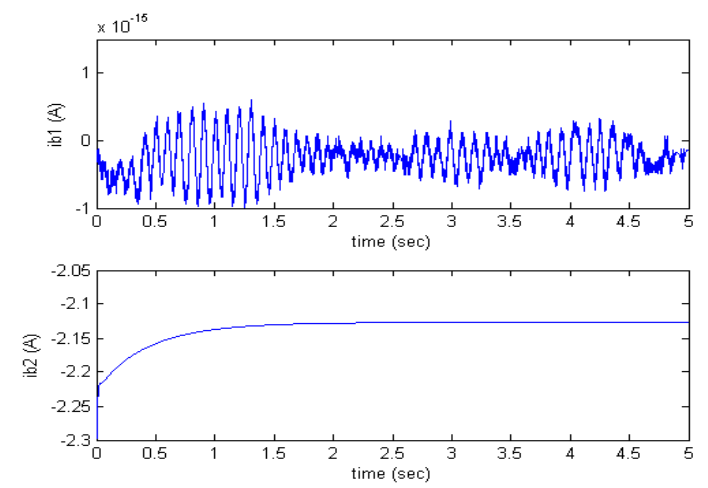

Figure 5. The bearing currents at the levitation stage.
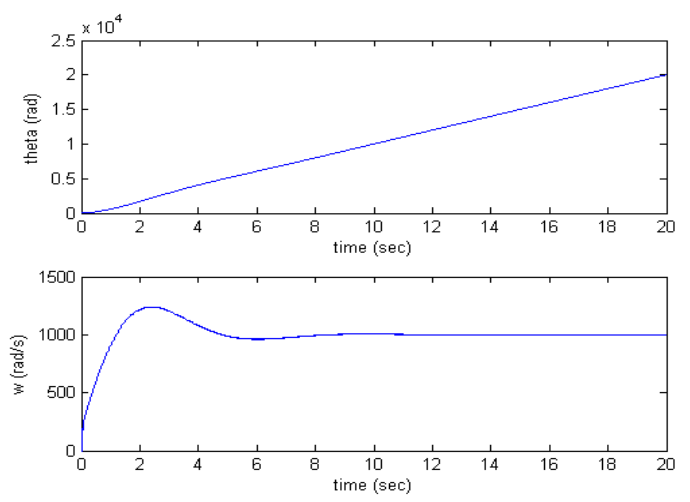

Figure 6 . The angular position and speed of the rotor at the rotation stage with speed command of $1000 \mathrm{rad} / \mathrm{s}$.

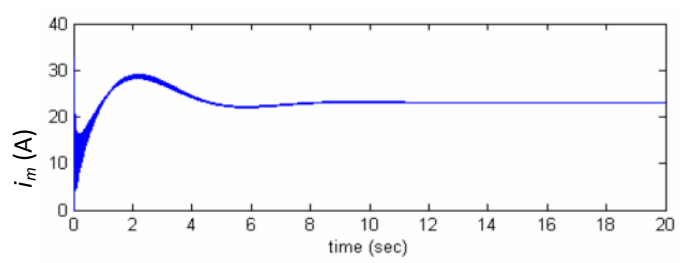

Figure 7. The motor currents at the rotation stage with speed command of $1000 \mathrm{rad} / \mathrm{s}$. 


\section{Conclusion}

A PM type bearingless motor has been proposed based on a 3-pole AMB. The dynamic model was obtained through the analysis of levitation forces and rotational torque. Controllers for stable levitation and rotor speed control were designed accordingly. The simulation results indicate that the conventional 3-pole AMB can be easily integrated with the 3-phase currents to become a bearingless motor.

\section{Acknowledgement}

This work is supported by the National Science Council of Taiwan, ROC, under the Grant NSC 99-3113-P-194-001.

\section{References}

[1] S. L. Chen, S. H. Chen, and S. T. Yan, "Experimental validation of a current-controlled three-pole magnetic rotor-bearing system," IEEE Transactions on Magnetics, vol. 41, no. 1, pp. 99-112, 2005. doi: 10.1109/TMAG.2004.839735

[2] S. L. Chen and C. T. Hsu, "Optimal design of a three-pole active magnetic bearing," IEEE Transactions on Magnetics, vol. 38, no. 5, pp. 3458-3466, 2002. doi: 10.1109/TMAG.2002.802709

[3] A. Chiba, M. Hanazawa, T. Fukao, and M. A. Rahman, "Effects of magnetic saturation on radial force of bearingless synchronous reluctance motors," IEEE Transactions on Industry Applications, vol. 32, no. 2, pp. 354-362, 1996. doi: $10.1109 / 28.491484$

[4] A. Chiba, M. A. Rahman, and T. Fukao, "Radial force in a bearingless reluctance motor," IEEE Transactions on Magnetics, vol. 27, no. 2, pp. 786-790, 1991. doi: $10.1109 / 20.133292$

[5] C. Michioka, T. Sakamoto, O. Ichikawa, A. Chiba, and T. Fukao, "A decoupling control method of reluctance-type bearingless motors considering magnetic saturation," IEEE Transactions on Industry Applications, vol. 32, no. 5, pp. 1204-1210, 1996.

doi: $10.1109 / 28.536884$

[6] M. Takemoto, A. Chiba, and T. Fukao, "A method of determining the advanced angle of square-wave currents in a bearingless switched reluctance motor," IEEE Transactions on Industry Applications, vol. 37, no. 6, pp. 1702-1709, 2001. doi: $10.1109 / 28.968181$
[7] M. Takemoto, H. Suzuki, A. Chiba, T. Fukao, and M. A. Rahman, "Improved analysis of a bearingless switched reluctance motor," IEEE Transactions on Industry Applications, vol. 37, no. 1, pp. 26-34, 2001.

doi: $10.1109 / 28.903123$

[8] A. Chiba, T. Deido, T. Fukao, and M. A. Rahman, "An analysis of bearingless ac motors," IEEE Transactions on Energy Conversion, vol. 9, no. 1, pp. 61-68, 1994.

doi: $10.1109 / 60.282477$

[9] A. Chiba and T. Fukao, "Optimal design of rotor circuits in induction type bearingless motors," IEEE Transactions on Magnetics, vol. 34, no. 4, pp. 2108-2110, 1998. doi: $10.1109 / 20.706817$

[10] A. Chiba, R. Furuichi, Y. Aikawa, K. Shimada, Y. Takamoto, and T. Fukao, "Stable operation of induction-type bearingless motors under loaded conditions," IEEE Transactions on Industry Applications, vol. 33, no. 4, pp. 919-924, 1997. doi: $10.1109 / 28.605733$

[11] A. Chiba, D. T. Power, and M. A. Rahman, "Characteristics of a bearingless induction motor," IEEE Transactions on Magnetics, vol. 27, no. 6, pp. 5199-5201, 1991. doi: $10.1109 / 20.278786$

[12] A. Chiba, D. T. Power, and M. A. Rahman, "Analysis of no-load characteristics of a bearingless induction motor," IEEE Transactions on Industry Applications, vol. 31, no. 1, pp. 77-83, 1995. doi: $10.1109 / 28.363047$

[13] A. O. Salazar and R. M. Stephan, "A bearingless method for induction machines," IEEE Transactions on Magnetics, vol. 29, no. 6, pp. 2965-2967, 1993. doi: $10.1109 / 20.280902$

[14] J. A. Santisteban and R. M. Stephan, "Analysis and control of a loaded bearingless machine," IEEE Transactions on Magnetics, vol. 35, no. 5, pp. 3998-4000, 1999. doi: $10.1109 / 20.800734$

[15] T. Suzuki, A. Chiba, M. Azizur Rahman, and T. Fukao, "An air-gap-flux-oriented vector controller for stable operation of bearingless induction motors," IEEE Transactions on Industry Applications, vol. 36, no. 4, pp. 1069-1076, 2000. doi: $10.1109 / 28.855962$

[16] W. Amrhein, S. Silber, and K. Nenninger, "Levitation forces in bearingless permanent magnet motors," IEEE Transactions on Magnetics, vol. 35, no. 5, pp. 4052-4054, 1999. doi: $10.1109 / 20.800752$

[17] M. Ooshima, A. Chiba, T. Fukao, and M. A. Rahman, "Design and analysis of permanent magnet-type bearingless motors," IEEE Transactions on Industrial Electronics, vol. 43, no. 2, pp. 292-299, 1996.

doi: $\underline{10.1109 / 41.491353}$ 
[18] O. Ichikawa, A. Chiba, and T. Fukao, "Inherently decoupled magnetic suspension in homopolar-type bearingless motors," IEEE Transactions on Industry Applications, vol. 37, no. 6, pp. 1668-1674, 2001. doi: $\underline{10.1109 / 28.968177}$

[19] M. Ooshima, A. Chiba, A. Rahman, and T. Fukao, "An improved control method of buried-type IPM bearingless motors considering magnetic saturation and magnetic pull variation," IEEE Transactions on Energy Conversion, vol. 19, no. 3, pp. 569-575, 2004.

doi: $10.1109 /$ TEC. 2004.832065

[20] J. Amemiya, A. Chiba, D. G. Dorrell, and T. Fukao, "Basic characteristics of a consequent-pole-type bearingless motor," IEEE Transactions on Magnetics, vol. 41, no. 1, pp. 82-89, 2005. doi: $\underline{10.1109 / T M A G .2004 .840179}$
[21] M. A. Casemore and L. S. Stephens, "Actuator gains for a toothless permanent-magnet self-bearing motor," IEEE Transactions on Magnetics, vol. 35, no. 6, pp. 4482-4489, 1999. doi: $10.1109 / 20.809141$

[22] L. S. Stephens and D. G. Kim, "Force and torque characteristics for a slotless Lorentz self-bearing servomotor," IEEE Transactions on Magnetics, vol. 38, no. 4, pp. 1764-1773, 2002. doi: $10.1109 /$ TMAG.2002.1017769 